\title{
Embodied Rhythm: Commentary on "The Contribution of Anthropometric Factors to Individual Differences in the Perception of Rhythm" by Neil P. McAngus Todd, Rosanna Cousins, and Christopher S. Lee
}

\author{
BRUNO H. REPP \\ Haskins Laboratories, New Haven \\ Rutgers University, Newark
}

\begin{abstract}
Todd, Cousins, and Lee (2007) have presented some intriguing data suggesting that body size, as measured by standard anthropometric indices, is related to the preferred beat period in a perceptual task. Curiously, however, they did not find a significant sex difference, even though the women in their sample were clearly smaller than the men. Another recent study of preferred spontaneous tempo (McAuley et al., 2006) likewise failed to find a sex difference in a large sample of young adults. It is unclear why body size should have an effect only within each sex group.
\end{abstract}

Submitted 2006 November 6; accepted 2006 November 6

KEYWORDS: rhythm, embodiment, resonance

ONE of the most exciting recent developments in psychological research and theorizing has been a resurgence of interest in the close relationship between perception and action. Researchers find that perception, rather than being the achievement of modular sensory and cognitive systems, is often grounded in actions that we need to carry out in our daily lives (see, e.g., Proffitt, 2006). Actions in turn need to be planned, guided, and confirmed by perception. Evidence is mounting that perception and action share a common code in the brain (Hommel et al., 2001), and brain areas in which that code resides are being identified (e.g., Rizzolatti \& Arbib, 1998; Iacoboni et al., 1999). Prior to recent developments, ecological psychologists already emphasized the close link between perception and action (e.g., Turvey, 1977). Actions depend on properties, limitations, and current states of our bodies, and so perception may also reflect those properties, limitations, and states.

Working at the fringes of the psychological mainstream, in part because of their interest in music and rhythm, Neil Todd and his collaborators have nevertheless made significant contributions to that general trend. Their research has consistently emphasized the role of the human body in rhythm perception and music performance (e.g., Todd, 1992, 1995; Todd \& Cody, 2000; Todd, O’Boyle, \& Lee, 1999; Todd, Lee, \& O'Boyle, 2002). The present paper constitutes an interesting addition to this work. Todd, Cousins, and Lee (2007, TCL henceforth) make the claim that people's body size affects their perception of rhythm and offer data in support of this hypothesis.

The perceptual task used to assess participants' preferred beat rate is clever. By using the names of three familiar tunes as response labels, TCL avoided having to ask participants to tap along with the anapest rhythms, which would have been an alternative (but perhaps less reliable?) method. Although it seems unlikely to me that all participants were familiar with Rossini's William Tell Overture (TCL say they asked participants but do not say what their answers were), participants were played examples of the three target categories at the beginning of the experiment. An estimate of preferred beat rate (really, of the preferred beat period) was obtained from the cumulative probability of responses in the center category ("Jingle Bells") as a function of beat period (for that tune). Basically, this is an estimate of the center (median) of the "Jingle Bells" category and may represent the preferred beat period for that tune rather than a general preference. The mean value of $540 \mathrm{~ms}$, however, is in reasonable agreement with other studies that used different methods to obtain estimates of preferred tempo or beat period (e.g., McAuley et al., 2006; Parncutt, 1994; Van Noorden \& Moelants, 1999). 
The perceptual test was administered twice and proved to be reasonably reliable. Male participants, however, chose significantly longer periods when they were retested, whereas female participants showed a tendency in the opposite direction. Because of this unexplained difference, TCL later refer to the men as less reliable and more variable than the women, although their test-retest correlation may not have been lower. One noteworthy finding is that, overall, males and females did not differ significantly in their preferred beat period. Perhaps they did differ when they were retested, but no separate statistical comparison is reported. Men also showed a slowing down with age, whereas women did not.

TCL related their perceptual data to a set of seven anthropometric measurements. Six of these were highly correlated and represented a single factor in a factor analysis; basically, they represent body size. One variable (biiliac breadth, or hip width) was less correlated with the others but did not account for any variance in the perceptual data. The likely reason for this is that women have smaller body sizes but relatively broader hips than men, which leads to a similar range of hip widths in both sexes (cf. Table 1). Apparently, the correlations (Table 2) and the factor analysis were computed for men and women combined, which explains why there were two factors. Within each sex group, hip width might have shown a higher correlation with body size.

The main finding of the study is that four of the six correlated anthropometric variables explained a significant amount of variance in the perceptual data, such that individuals with larger body size tended to have longer preferred beat periods. Although significant, the effects were not large, accounting for maximally $16 \%$ of the variance. TCL say that "it would be surprising if the relationship between anthropometric factors and perception was stronger than the relationship between anthropometric factors and action." In that connection, it is regrettable that TCL did not include a measure of walking speed in their study in order to investigate whether there is a closer relationship between that variable and preferred tempo than between the anthropometric variables and preferred tempo. Clearly, some specific periodic action(s) must constitute the link between static properties of the body and perceptual judgments, and walking may be that action (or one of these actions).

TCL discuss their finding that young men, according to the perceptual judgments, seem to slow down with age, whereas young women do not. TCL note that young men have a slower pattern of growth and argue that sensorimotor recalibration may lag behind physical growth by one year or so. While this is an intriguing possibility, the age effect tends to divert attention from what for me is the major puzzle of this study: Why did men not show a preference for a slower beat compared to women? The men were clearly larger than the women according to all anthropometric measures except hip width (Table 1), yet they seemed to prefer a similar beat (Table 3a). To explain the absence of a sex difference in perception, the male lag in sensorimotor recalibration presumably would have to be longer than one year. Also, for that explanation to hold, the lack of a sex difference would have to be specific to very young adults. Perhaps a sex difference would be found in somewhat older participants? It should also be recalled that the male participants in the present study slowed down when they were retested, so perhaps there was a sex difference, after all.

However, McAuley et al. (2006) recently reported a life-span study of timing and event tracking that included measurements of spontaneous motor tempo (tapping) and of preferred perceptual tempo (judgment of isochronous sequences), which were strongly correlated. No sex difference was mentioned, and Devin McAuley (personal communication, 10/31/06) has confirmed that the sex difference was not even remotely close to significance in his sample of 119 young adults (ages 18-38). This finding constitutes a challenge to the results of TCL, for their hypothesis surely must predict a sex difference in a sufficiently large sample of adults, given that women are significantly smaller than men.

TCL deliberately excluded obese individuals from their study, but it is not clear why. They meant to achieve "greater homogeneity" of their sample, but this worked against their hypothesis. Since heavy individuals presumably walk slower than slim people, they also should show a preference for slower beats. This prediction remains to be tested.

In a series of ingenious experiments, Dennis Proffitt and his students have demonstrated that visual perception is influenced by the momentary state of the observer's body (see Proffitt, 2006, for a review). For example, people judge a hill to be steeper when they are wearing a heavy backpack or after strenuous exercise (Bhalla \& Proffitt, 1999). TCL, by contrast, seem to be assuming that preference for a particular beat period is determined (or at least influenced) by long-term properties of the body. Yet, Proffitt's results raise the interesting question whether beat preferences in rhythm perception might also depend on the momentary state of the body. Would participants who are tired from exercise or are carrying a heavy load prefer a slower beat than those who are fresh and agile? These would be interesting 
experiments to conduct, and the results might show that beat perception is more flexible than TCL's skeletal approach suggests.

\section{REFERENCES}

Bhalla, M., \& Proffitt, D. (1999). Visual-motor recalibration in geographical slant perception. Journal of Experimental Psychology: Human Perception and Performance, Vol. 25, pp. 1076-1096.

Hommel, B., Müsseler, J., Aschersleben, G., \& Prinz, W. (2001). The Theory of Event Coding (TEC): A framework for perception and action planning. Behavioral and Brain Sciences, Vol. 24, pp. 849-937.

Iacoboni, M., Woods, R. P., Brass, M., Bekkering, H., Mazziotta, J. C., \& Rizzolatti, G. (1999). Cortical mechanisms of human imitation. Science, Vol. 286, pp. 2526-2528.

McAuley, J. D., Jones, M. R., Holub, S., Johnston, H. M., \& Miller, N. S. (2006). The time of our lives: Life span development of timing and event tracking. Journal of Experimental Psychology: General, Vol. 135, pp. 348-367.

Parncutt, R. (1994). A perceptual model of pulse salience and metrical accent in musical rhythms. Music Perception, Vol. 11, pp. 409-464.

Proffitt, D. R. (2006). Embodied perception and the economy of action. Perspectives on Psychological Science, Vol. 1, pp. 110-122.

Rizzolatti, G., \& Arbib, M. A. (1998). Language within our grasp. Trends in Neuroscience, Vol. 21, pp. 188-194.

Todd, N. P. McA. (1992). The dynamics of dynamics: A model of musical expression. Journal of the Acoustical Society of America, Vol.91, pp. 3540-3550.

Todd, N. P. McA. (1995). The kinematics of musical expression. Journal of the Acoustical Society of America, Vol. 97, pp. 1940-1949.

Todd, N. P. McA. \& Cody, F. W. (2000). Vestibular responses to loud dance music: A physiological basis of the "rock and roll threshold"? Journal of the Acoustical Society of America, Vol. 107, pp. 496-500.

Todd, N. P. McA., Cousins, R., \& Lee, C.S. (2007). The contribution of anthropometric factors to individual differences in the perception of rhythm. Empirical Musicology Review, Vol. 2 No. 1, pp. 1-13.

Todd, N. P. McA., Lee, C. S., \& O'Boyle, D. J. (2002). A sensorimotor theory of temporal tracking and beat induction. Psychological Research, Vol. 66, pp. 26-39.

Todd, N. P. McA., O'Boyle, D. J., \& Lee, C. S. (1999). A sensory-motor theory of rhythm, time perception and beat induction. Journal of New Music Research, Vol. 28, pp. 5-28.

Turvey, M. T. (1977). Preliminaries to a theory of action with reference to vision. In R. Shaw \& J. Bransford (Eds.), Perceiving, Acting, and Knowing (pp. 211-266). Hillsdale, NJ: Erlbaum.

Van Noorden, L., \& Moelants, D. (1999). Resonance in the perception of musical pulse. Journal of New Music Research, Vol. 28, pp. 43-66. 